\title{
Continuous Glucose Monitoring and Global Reimbursement: An Update
}

\author{
Claudia Graham, PhD, MPH
}

\begin{abstract}
Real-time continuous glucose monitoring has been available for a decade and reimbursement for the technology has been slowly growing. Reasons for the various rates of reimbursement and adoption are explored in this article and the status of country-wide reimbursement is discussed.
\end{abstract}

Keywords: Continuous glucose monitoring, Reimbursement, Cost-effectiveness analysis.

\section{Introduction}

$\mathbf{P}$ ERSONAL USE CONTINUOUS glucose monitoring (CGM), also called real-time CGM (RT-CGM), has been demonstrated to reduce hyperglycemia and hypoglycemia by providing patients with real-time actionable information about their current blood glucose levels, the rate and direction of glucose changes, and alerts/alarms when blood glucose values exceed or fall below specified thresholds. ${ }^{1}$ Randomized controlled trials (RCTs) have shown that RT-CGM significantly lowers HbA1c without increasing the risk of hypoglycemia in patients with type 1 diabetes mellitus (T1DM) and that efficacy is correlated with frequency of CGM use. ${ }^{2-4}$ Guidelines and position statements support the use of RT-CGM in patients with T1DM and in selected patients with type 2 diabetes (T2DM) ${ }^{5-9}$ and many experts believe that CGM will eventually replace traditional self-monitoring of blood glucose (SMBG) in intensively managed patients.

Although RT-CGM has been available for more than a decade, and the evidence base for its clinical efficacy has grown, adoption has been relatively low, particularly outside the United States, and coverage by global reimbursement authorities has been limited. ${ }^{11}$ Barriers to more widespread reimbursement of RT-CGM include (1) lack of independent, robust, randomized clinical trials demonstrating both improved outcomes for hyperglycemia and hypoglycemia in specific patient populations; (2) a relatively insufficient evidence base about the value of RT-CGM in patients receiving multiple daily insulin injections (MDI) versus use of RT-CGM in combination with insulin pump therapy; and (3) limited published data on cost-effectiveness ${ }^{11,1}$ This article reviews the current status of reimbursement of RT-CGM in industrialized countries as well as major barriers to broader reimbursement.

\section{Status of RT-CGM Global Coverage and Reimbursement}

Table 1 summarizes the current status of RT-CGM global reimbursement.

\section{United States}

Nearly all commercial payers, covering $\sim 200$ million lives, have issued positive RT-CGM coverage determinations for patients with T1DM and about a quarter have positive coverage policies for insulin-taking type 2 diabetes patients. The government funds most of the remaining U.S. population through entitlement programs such as Medicare and Medicaid.

In early 2017, the Centers for Medicaid and Medicare Services (CMS) issued an administrative ruling (CMS 1682-R) declaring that "therapeutic" CGM will be eligible for Medicare coverage. ${ }^{12}$ Therapeutic CGM was defined as FDAapproved CGM devices that provide information to patients that can be used to make diabetes treatment decisions without confirmatory finger-stick testing (also called finger-stick replacement or nonadjunctive use). Coverage criteria include intensively managed insulin-taking patients who perform four or more SMBG/day, are taking multiple insulin injections or using an insulin pump, and will require frequent adjustment of insulin based on the reading from the therapeutic CGM. 
Table 1. Current Status of Global Real-Time Continuous Glucose Monitoring Coverage and ReImbursement

\begin{tabular}{|c|c|c|c|}
\hline Country & Funding model & Payer & Coverage/reimbursement of RT-CGM \\
\hline \multirow[t]{2}{*}{ United States } & Employers & Commercial & $\begin{array}{l}\text { Yes for T1DM and some for } \\
\text { insulin-requiring T2DM }\end{array}$ \\
\hline & Government & Medicare & Yes for "therapeutic CGM", \\
\hline United Kingdom & National taxes & National Health Service & $\begin{array}{l}\text { Limited coverage for sensor-augmented } \\
\text { pump through NICE recommendation; } \\
\text { regional clinical commission groups } \\
\text { for standalone RT-CGM. }\end{array}$ \\
\hline Sweden & $\begin{array}{l}\text { Social system funded } \\
\text { from contributions } \\
\text { by employees }\end{array}$ & Tenders; regional & $\begin{array}{l}\text { Yes; coverage available through regions; } \\
\text { not on the national approved list }\end{array}$ \\
\hline Norway & $\begin{array}{l}\text { Social system funded } \\
\text { from contributions } \\
\text { by employees }\end{array}$ & Tenders; regional & $\begin{array}{l}\text { Yes; coverage available through regions; } \\
\text { not on the national approved list }\end{array}$ \\
\hline France & $\begin{array}{l}\text { Social system funded } \\
\text { from contributions } \\
\text { by employees }\end{array}$ & HAS; national & $\begin{array}{l}\text { Positive health technology assessment; } \\
\text { no reimbursement in place yet } \\
\text { for RT CGM }\end{array}$ \\
\hline Germany & $\begin{array}{l}\text { Social system funded } \\
\text { from contributions } \\
\text { by employees }\end{array}$ & G-BA; national & RT-CGM for T1DM and T2DM \\
\hline Switzerland & Private insurance & National & Yes \\
\hline Italy & National taxes & Provincial (Regional) & $\begin{array}{l}\text { Full reimbursement in Piemonte and } \\
\text { Basalicata; individual case } \\
\text { determinations elsewhere }\end{array}$ \\
\hline Spain & National taxes & Provincial & No \\
\hline Belgium & $\begin{array}{l}\text { Social system funded } \\
\text { from contributions } \\
\text { by employees }\end{array}$ & Regional & $\begin{array}{l}\text { Partial funding through hospital DRG } \\
\text { (Care Pathways) }\end{array}$ \\
\hline Slovenia & National taxes & National & Yes; pediatrics only \\
\hline The Netherlands & $\begin{array}{l}\text { Social system and } \\
\text { private insurance }\end{array}$ & National & $\begin{array}{l}\text { RT-CGM available through hospital } \\
\text { DRG systems }\end{array}$ \\
\hline Czech Republic & National taxes & $\begin{array}{l}\text { National; patient } \\
\text { capitation }\end{array}$ & $\begin{array}{l}\text { Partial reimbursement for receivers } \\
\text { and transmitters; patient copay }\end{array}$ \\
\hline Slovakia & National taxes & National & Limited to pediatrics; patient co-pay \\
\hline South Africa & Private insurance & $\begin{array}{l}\text { Individual funding } \\
\text { request-funded } \\
\text { from patients' savings } \\
\text { insurance plan }\end{array}$ & $\begin{array}{l}\text { Reimbursed up to savings limit; } \\
\text { patient co-pay }\end{array}$ \\
\hline Israel & $\begin{array}{l}\text { Universal medical } \\
\text { insurance plans }\end{array}$ & Regional & Yes; fully funded for pediatrics \\
\hline
\end{tabular}

DRG, diagnosis-related group; GBA, Gemeinsamer Bundesausschuss (Federal Joint Committee); HAS, Haute Autorité de Santé (French National Authority for Health); NICE, National Institute for Health and Care Excellence; RT-CGM, real-time continuous glucose monitoring.

To receive commercial coverage for RT-CGM, policies typically require some type of "certificate of medical necessity" from the treating clinician stating the patient has poorly controlled diabetes (e.g., HbA1c more than target level, history of recurrent and/or severe hypoglycemia, and history of diabetic ketoacidosis) despite receiving best practices treatment. Some commercial coverage policies do not require this certificate and the clinician may simply write a prescription to initiate RT-CGM.

Examples of RT-CGM coverage policies by two large U.S. commercial payers, which are largely representative of commercial payers' stance toward RT-CGM, are summarized hereunder. The Blue Cross Blue Shield Federal Employees Health Plan, which covers 4,300,000 federal employees and dependents, considers RT-CGM to be medically necessary when the following situations occur despite use of best practices:

1. patients with T1DM have recurrent, unexplained, severe (generally blood glucose levels less than $50 \mathrm{mg} / \mathrm{dL}$ ) hypoglycemia that puts the patient or others at risk; or
2. pregnant patients have poorly controlled T1DM, which includes unexplained hypoglycemic episodes, hypoglycemic unawareness, suspected postprandial hyperglycemia, or recurrent diabetic ketoacidosis.

Aetna, a large commercial payer with $\sim 20$ million members, covers RT-CGM when medically necessary in adults aged 25 years and older with T1DM and in younger persons with T1DM who have had recurrent episodes of severe hypoglycemia despite appropriate modifications to their insulin regimen and compliance with self-monitoring of blood glucose (at least 4 finger-sticks/day).

\section{Reimbursement Outside of the United States}

\section{Canada}

Some private payers in Canada have reimbursement policies for RT-CGM, but most health services provided in $\mathrm{Ca}-$ nada are funded by the government and decisions regarding 
reimbursement of RT-CGM are made by individual provincial health authorities. Ontario is the largest province in Canada and has a well-defined health technology assessment program, the Ontario Health Technology Advisory Committee (OHTAC), which often serves as the bellwether for other provinces. In 2011, an OHTAC evaluation of RT-CGM concluded that there was no compelling data to support reimbursement. ${ }^{13}$ In 2017, the OHTAC began a new evaluation of RT-CGM that presumably will include more recently published clinical and cost-effectiveness studies; the final decision regarding reimbursement of RT-CGM is expected in late 2017.

\section{Australia}

Government funding through the National Diabetes Services Scheme for RT-CGM (which is limited to devices that have real-time alerts and alarms) began in early 2017 and will initially focus on the pediatric population $(<21$ years $)$ who meet age-specific criteria. This reimbursement coverage decision was due in large part to the efforts by patient and professional advocacy organizations in Australia.

\section{Europe}

In Europe, gaining approval for commercialization of medical devices (Conformité Europeène [CE] mark) is typically a faster process than in the United States. As a result, medical device manufacturers often will launch a new product in the European Union (EU) before commercialization in the United States. However, approval by a regulatory agency does not guarantee that a product will be widely accessible in the market; rather, broad reimbursement by a national or third party payer is needed to provide access. The average time between EU product approval and broad country-level reimbursement ranges from 1 to 6 years. Because most countries in the EU have publicly financed healthcare systems, with each country making its own decisions about reimbursement, criteria vary considerably across member nations. Efforts are underway by European medical technology organizations to standardize requirements for health technology assessments, but harmonization of requirements is not expected soon.

Unlike U.S. payers, which primarily focus on clinical effectiveness in decisions regarding coverage, the EU payers often consider both clinical evidence and economic impact when evaluating products for reimbursement. Generating high-quality evidence to support reimbursement of new medical devices poses challenges because of relatively rapid technological innovation and short product lifecycles. In the United Kingdom, the National Institute for Health and Care Excellence (NICE) has a defined medical technology appraisal process; NICE assessments are used by the National Healthcare Service to inform funding priorities. NICE clinical guidelines (NG17 and NG18) ${ }^{9}$ provide guidance for RTCGM use in subsets of adults and children who present with clinical criteria, such as impaired awareness of hypoglycemia, extreme fear of hypoglycemia, or hyperglycemia (HbA1c level of $75 \mathrm{mmol} / \mathrm{mol}$ [9\%] or higher) that persists despite conducting finger-stick tests at least 10 times per day. In 2015, NICE issued a diagnostic guidance document (DG21) for sensor-augmented pump therapy, which includes T1DM patients who have episodes of disabling hypoglycemia de- spite optimal management with continuous subcutaneous insulin infusion. $^{10}$

In Germany, the determination for coverage is driven primarily by the clinical evidence. The Institute for Quality and Efficiency in Health Care is an independent scientific institute that may only accept commissions from the Federal Ministry of Health or Federal Joint Committee (G-BA), which is the highest decision-making body of the selfgovernment of physicians, dentists, hospitals, and health insurance funds in German Health Care. The G-BA decides which medical services will be reimbursed by the statutory health insurance funds. In 2016, the G-BA announced RTCGM will be reimbursed for insulin-dependent type 1 and type 2 patients.

Other countries have various reimbursement assessment criteria, but fundamentally focus on RCTs, economic modeling, and real-world evidence. Some EU countries are considering "coverage with evidence determination" as well as "performance-based risk sharing agreements" for new pharmaceuticals and perhaps for medical devices.

\section{Barriers to Reimbursement of RT-CGM}

\section{Evidence for reducing hypoglycemia events}

Clinical evidence from RCTs supports the efficacy of RTCGM for reducing $\mathrm{HbA} 1 \mathrm{c}$ in both well-controlled and poorly controlled T1DM patients without increasing the risk for hypoglycemia. ${ }^{14-26}$ The primary goal of most clinical studies of RT-CGM conducted to date has been to demonstrate that the technology significantly reduces HbA1c even though these devices also should decrease the risk of hypoglycemia, which is a major barrier to patients achieving glycemic targets. $^{27}$ Although several studies have shown that use of RTCGM significantly reduces time spent in hypoglycemia in T1DM patients, ${ }^{14,16,28}$ initial RCTs evaluating RT-CGM were not designed or adequately powered to determine the efficacy of RT-CGM for reducing the frequency of hypoglycemic events in general and severe hypoglycemic events in particular. Patients at high risk for severe hypoglycemia (those with a history of severe hypoglycemia or hypoglycemia unawareness) were purposely excluded from the trials and the study sample sizes were not large enough to compare the incidence of severe hypoglycemia, which is a relatively infrequent event.

For some reimbursement authorities, reducing the frequency of hypoglycemic events is a key outcome for determining the clinical value of RT-CGM. A recently published randomized, open-label crossover design study examined the effects of RT-CGM on time spent in normoglycemia (70$180 \mathrm{mg} / \mathrm{dL}$; primary end point) and incidence of severe hypoglycemia (requiring third party assistance; secondary end point) in patients with T1DM and impaired awareness of hypoglycemia in The Netherlands. ${ }^{29}$ Patients spent significantly more time in normoglycemia (65\% vs. $55.4 \%$, $P<0.0001)$ and had significantly fewer severe hypoglycemic events (14 events vs. 34 events, $P=0.033$ ) when using RTCGM than when self-monitoring blood glucose. These findings indicate that RT-CGM can reduce the incidence of severe hypoglycemic events in a high-risk population. Large clinical trials involving patients with a wide range of risk for hypoglycemia are needed to address the question of whether 


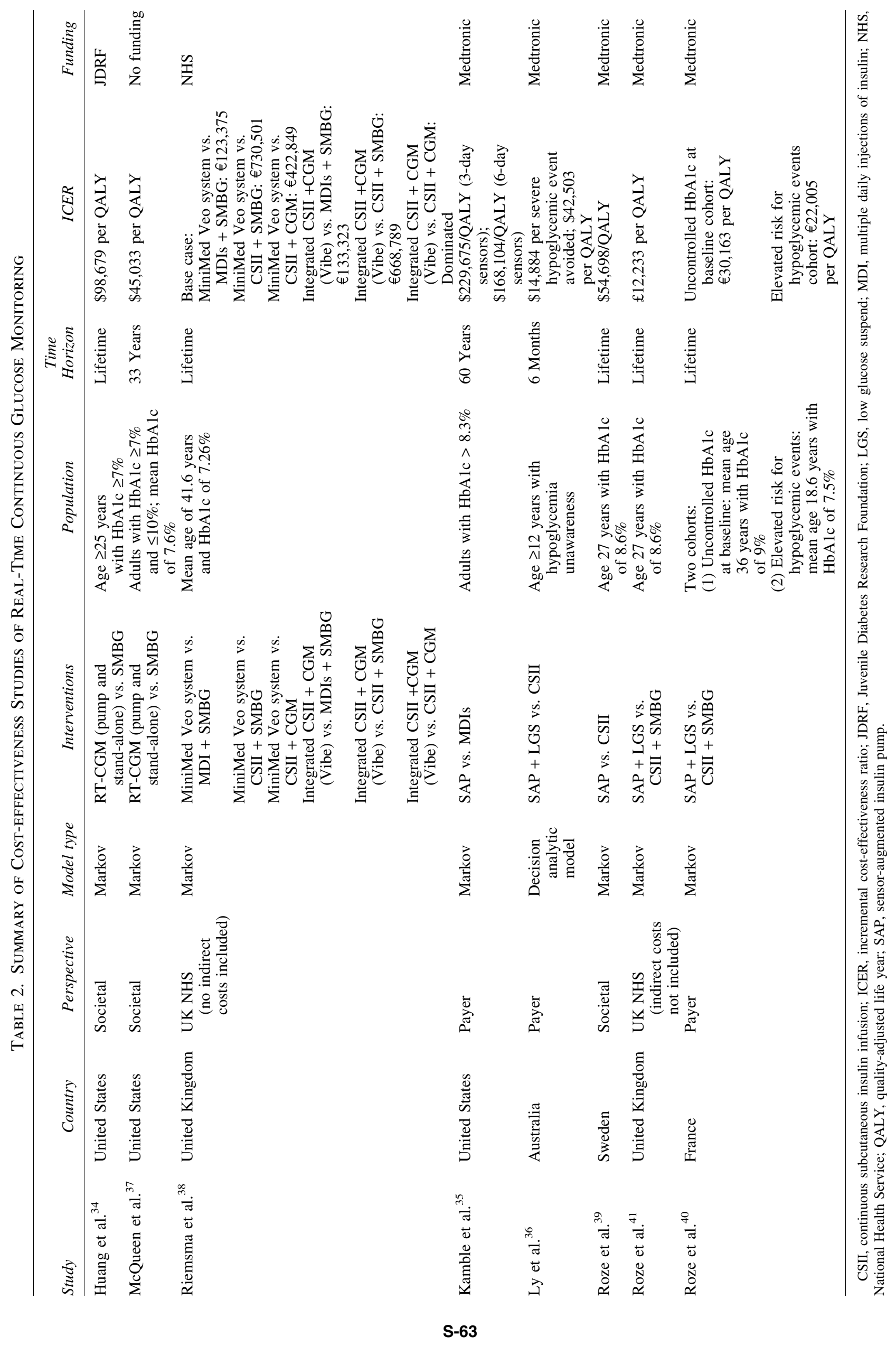


the technology can reduce the incidence of severe hypoglycemic events in nonselected patients.

\section{Value of RT-CGM in patients using MDI}

Until recently, the preponderance of RT-CGM research has involved intensively managed insulin-treated patients receiving insulin pump therapy in combination with RTCGM (sensor-augmented pump therapy). However, rates of insulin pump use among patients with T1DM vary internationally, ranging from $<10 \%$ in some European countries to up to $38 \%$ of patients in select populations in the United States,${ }^{30,31}$ with the majority of patients often treated with multiple daily injections (MDI). Because studies of sensoraugmented pump therapy are unable to determine the independent contributions of the technology components, it is increasingly important to evaluate the contribution of RTCGM as a standalone intervention in patients receiving MDI, as has been done in several recently published RCTs. ${ }^{16,22}$ These studies show that standalone RT-CGM is significantly more effective than conventional blood glucose monitoring in patients with T1DM treated with MDI, reducing $\mathrm{HbA} 1 \mathrm{c}$ by $-0.43 \%$ to $-0.60 \%$. In addition, a prospective, nonrandomized, real-life clinical trial demonstrated that RT-CGM combined with either insulin pump therapy or MDI provided a comparable and significant reduction in HbAlc in comparison with the combination of insulin pump therapy/MDI and self-monitoring of blood glucose. ${ }^{32}$

\section{Cost and Evidence of Cost-Effectiveness}

Cost-effectiveness analyses (CEAs), including cost-utility analysis, are integral components of reimbursement considerations in many countries outside of the United States. Budget impact analysis (BIA) is often also required both in and outside of the United States. When conducting a BIA of RT-CGM, it is important to consider costs that may result from failure to give patients access to RT-CGM, including the risk for short-term morbidity and mortality, costs of emergency treatment for severe hypoglycemic episodes (ambulance/EMS services, emergency department visits, and hospital admissions), and costs of long-term complications associated with poorly controlled diabetes.

CEAs and cost-utility analyses are important to capture the potential cost offsets of RT-CGM associated with reducing the risk of long-term diabetes complications, which may not develop until decades after diagnosis. CEA models depend on robust clinical data and, therefore, may not be completed and published until years after a new technology has been evaluated in clinical trials and commercialized. Because RTCGM technology is developing at a rapid rate (with new versions of RT-CGM showing improvements in accuracy and usability), CEAs may be obsolete by the time clinical data for new devices are published. ${ }^{33}$ In the past decade, eight publications have examined the cost-effectiveness of the RT-CGM in patients with T1DM (Table 2). ${ }^{34-41}$ The results of these studies are presented in terms of cost per qualityadjusted life year (QALY) or cost per hypoglycemic event avoided. Results are wide ranging, possibly because of differences in assumptions that form the basis of the models. It is important to note that these CEAs have only considered the costs associated with long-term diabetes complications because there has been little evidence that RT-CGM signifi- cantly impacts hypoglycemia, which is associated with both short- and long-term costs.

The results from CEA models of RT-CGM may not be compelling to payers for several reasons. First, most studies estimated the value of RT-CGM over a long time horizon (e.g., the patient's lifetime) even though the average retention of a U.S. commercial health plan member is typically a few years, and U.S. payers traditionally focus on 1-3-year periods corresponding to their budget and contracting cycles. ${ }^{42} \mathrm{Sec}-$ ond, almost all economic models of RT-CGM are complex Markov models, which payers may not find credible because of the use of many assumptions or lack of transparency. ${ }^{43}$ Third, most studies reported the economic value of RT-CGM in terms of cost per QALY gained, which may have limited relevance, meaningfulness, validity, and reliability to all payers. ${ }^{44}$ Fourth, models based on a societal perspective (which include both direct and indirect costs) may not be relevant to payers who are exclusively concerned with direct costs. Thus, CEAs of RT-CGM must be adapted so they are relevant to individual payers and countries that often have different priorities and willingness-to-pay thresholds.

It is important to note that only two of the eight published CEAs evaluated standalone RT-CGM, ${ }^{34,37}$ whereas others evaluated sensor-augmented pump therapy ${ }^{35,36,38-41}$; the CEA performed by Huang et al. was based on outcomes from the Juvenile Diabetes Research Foundation trial, in which intervention group patients could have received either sensoraugmented insulin pump therapy or MDIs plus RT-CGM.

Difficulty understanding these CEAs may be because of several reasons. First, these analyses have been based on research that has not differentiated between methods of insulin delivery or types of RT-CGM devices. Second, the clinical data used for modeling may not be representative of results achieved in real-life settings. Lastly, patients' trust in the accuracy of their RT-CGM device may affect adherence and also prompt patients to become less reactive (reacting to alerts and alarms) and more proactive (using the data to anticipate glucose changes and respond early and aggressively) in managing their diabetes. ${ }^{45}$ There is ample evidence that the efficacy of RT-CGM is well correlated with adherence. ${ }^{18,20,21,23,28,46-51}$ Thus, it is reasonable to posit that more accurate RT-CGM devices could result in better efficacy. Because CEAs incorporated into health technology assessments typically include the entire category (i.e., all RT-CGM devices), these analyses may not reflect differences in outcomes related to device performance and patient compliance.

\section{Conclusion}

RT-CGM is becoming a standard of care for insulinrequiring patients in the United States, and is gaining greater acceptance in other industrialized nations. Access to RTCGM is expected to grow as more CEAs are combined with clinical evidence in select patient populations. Considerations for reimbursement should include RT-CGM used as a standalone device or as part of a sensor-augmented pump system, as well as when used as a necessary component of any artificial pancreas or closed loop system.

\section{Acknowledgment}

The author wishes to thank Amy Bronstone, PhD, for editorial support in developing this article. 


\section{Author Disclosure Statement}

Claudia Graham is an employee and shareholder of Dexcom, Inc.

\section{References}

1. Rodbard D: Continuous glucose monitoring: a review of successes, challenges, and opportunities. Diabetes Technol Ther 2016;18 Suppl 2:S23-S213.

2. Floyd B, Chandra P, Hall S, et al.: Comparative analysis of the efficacy of continuous glucose monitoring and selfmonitoring of blood glucose in type 1 diabetes mellitus. $\mathrm{J}$ Diabetes Sci Technol 2012;6:1094-1102.

3. Pickup JC, Freeman SC, Sutton AJ: Glycaemic control in type 1 diabetes during real time continuous glucose monitoring compared with self monitoring of blood glucose: meta-analysis of randomised controlled trials using individual patient data. BMJ 2011;343:d3805.

4. Yeh HC, Brown TT, Maruthur N, et al.: Comparative effectiveness and safety of methods of insulin delivery and glucose monitoring for diabetes mellitus: a systematic review and meta-analysis. Ann Intern Med 2012;157:336-347.

5. American Diabetes Association: Glycemic targets. Sec. 6. In Standards of Medical Care in Diabetes-2017. Diabetes Care 2017;40:S48-S56.

6. Bailey TS, Grunberger G, Bode BW, et al.: American Association of Clinical Endocrinologists and American College of Endocrinology 2016 Outpatient Glucose Monitoring Consensus Statement. Endocr Pract 2016;22:231-261.

7. Fonseca VA, Grunberger G, Anhalt H, et al.: Continuous glucose monitoring: a consensus conference of the American Association of Clinical Endocrinologists and American College of Endocrinology. Endocr Pract 2016;22: 1008-1021.

8. National Institute for Health and Care Excellence (NICE): Diabetes (type 1 and type 2 ) in children and young people: diagnosis and management. Guidelines [NG18]. Last updated November 2016. London, UK: National Institute for Health and Care Excellence, 2015.

9. National Institute for Health and Care Excellence (NICE): Type 1 diabetes in adults: diagnosis and management. NICE guideline [NG17]. Last updated July 2016. London, UK: National Institute for Health and Care Excellence, 2015. www.nice.org.uk/guidance/NG17 (accessed May 4, 2017).

10. National Institute for Health and Care Excellence (NICE): Integrated sensor-augmented pump therapy systems for managing blood glucose levels in type 1 diabetes (the MiniMed Paradigm Veo system and the Vibe and G4 PLATINUM CGM system). London, UK: National Institute for Health and Care Excellence, 2016.

11. Heinemann L, DeVries JH: Reimbursement for continuous glucose monitoring. Diabetes Technol Ther 2016;18 Suppl 2:S248-S252.

12. Centers for Medicare \& Medicaid Services: Ruling No. [CMS-1682-R]. 2017. www.cms.gov/Regulations-andGuidance/Guidance/Rulings/Downloads/CMS1682R.pdf (accessed January 29, 2017).

13. Ontario Health Technology Advisory Committee: Continuous Glucose Monitoring for Patients with Diabetes. 2011. www.hqontario.ca/Portals/0/Documents/evidence/ reports/recommendation-cgm-110630.pdf (accessed January 29,2017$)$.
14. Battelino T, Conget I, Olsen B, et al.: The use and efficacy of continuous glucose monitoring in type 1 diabetes treated with insulin pump therapy: a randomised controlled trial. Diabetologia 2012;55:3155-3162.

15. Beck RW, Hirsch IB, Laffel L, et al.: The effect of continuous glucose monitoring in well-controlled type 1 diabetes. Diabetes Care 2009;32:1378-1383.

16. Beck RW, Riddlesworth T, Ruedy K, et al.: Effect of continuous glucose monitoring on glycemic control in adults with type 1 diabetes using insulin injections: the DIAMOND randomized clinical trial. JAMA 2017;317:371-378.

17. Bergenstal RM, Tamborlane WV, Ahmann A, et al.: Effectiveness of sensor-augmented insulin-pump therapy in type 1 diabetes. N Engl J Med 2010;363:311-320.

18. Deiss D, Bolinder J, Riveline JP, et al.: Improved glycemic control in poorly controlled patients with type 1 diabetes using real-time continuous glucose monitoring. Diabetes Care 2006;29:2730-2732.

19. Hermanides J, DeVries JH: Sensor-augmented insulin pump more effective than multiple daily insulin injections for reducing $\mathrm{HbA1C}$ in people with poorly controlled type 1 diabetes. Evid Based Med 2011;16:46-48.

20. Hirsch IB, Abelseth J, Bode BW, et al.: Sensor-augmented insulin pump therapy: results of the first randomized treatto-target study. Diabetes Technol Ther 2008;10:377-383.

21. Juvenile Diabetes Research Foundation Continuous Glucose Monitoring Study Group: Effectiveness of continuous glucose monitoring in a clinical care environment: evidence from the Juvenile Diabetes Research Foundation continuous glucose monitoring (JDRF-CGM) trial. Diabetes Care 2010;33:17-22.

22. Lind M, Polonsky W, Hirsch IB, et al.: Continuous glucose monitoring vs conventional therapy for glycemic control in adults with type 1 diabetes treated with multiple daily insulin injections: the GOLD tandomized clinical trial. JAMA 2017;317:379-387.

23. O'Connell MA, Donath S, O'Neal DN, et al.: Glycaemic impact of patient-led use of sensor-guided pump therapy in type 1 diabetes: a randomised controlled trial. Diabetologia 2009;52:1250-1257.

24. Radermecker RP, Saint Remy A, Scheen AJ, et al.: Continuous glucose monitoring reduces both hypoglycaemia and $\mathrm{HbAlc}$ in hypoglycaemia-prone type 1 diabetic patients treated with a portable pump. Diabetes Metab 2010;36:409-413.

25. Riveline JP, Schaepelynck P, Chaillous L, et al.: Assessment of patient-led or physician-driven continuous glucose monitoring in patients with poorly controlled type 1 diabetes using basal-bolus insulin regimens: a 1-year multicenter study. Diabetes Care 2012;35:965-971.

26. Tamborlane WV, Beck RW, Bode BW, et al.: Continuous glucose monitoring and intensive treatment of type 1 diabetes. N Engl J Med 2008;359:1464-1476.

27. American Diabetes Association: Glycemic targets. Sec. 6. In Standards of Medical Care in Diabetes-2017. Diabetes Care 2017;40:S48-S56.

28. Battelino T, Phillip M, Bratina N, et al.: Effect of continuous glucose monitoring on hypoglycemia in type 1 diabetes. Diabetes Care 2011;34:795-800.

29. van Beers CA, DeVries JH, Kleijer SJ, et al.: Continuous glucose monitoring for patients with type 1 diabetes and impaired awareness of hypoglycaemia (IN CONTROL): a randomised, open-label, crossover trial. Lancet Diabetes Endocrinol 2016;4:893-902. 
30. Pickup JC: Are insulin pumps underutilized in type 1 diabetes? Yes. Diabetes Care 2006;29:1449-1452.

31. Tanenbaum ML, Hanes SJ, Miller KM, et al.: Diabetes device use in adults with type 1 diabetes: barriers to uptake and potential intervention targets. Diabetes Care 2017;40: 181-187.

32. Šoupal J, Petruželková L, Flekač M, et al.: Comparison of different treatment modalities for type 1 diabetes, including sensor-augmented insulin regimens, in 52 weeks of followup: a COMISAIR study. Diabetes Technol Ther 2016;18: 532-538.

33. Price D, Walker T, Graham C: Comment on Wong et al. Real-time continuous glucose monitoring among participants in the T1D exchange clinic registry. Diabetes Care 2014;37:2702-2709.

34. Huang ES, O'Grady M, Basu A, et al:: The costeffectiveness of continuous glucose monitoring in type 1 diabetes. Diabetes Care 2010;33:1269-1274.

35. Kamble S, Schulman KA, Reed SD: Cost-effectiveness of sensor-augmented pump therapy in adults with type 1 diabetes in the United States. Value Health 2012;15:632-638.

36. Ly TT, Brnabic AJ, Eggleston A, et al.: A costeffectiveness analysis of sensor-augmented insulin pump therapy and automated insulin suspension versus standard pump therapy for hypoglycemic unaware patients with type 1 diabetes. Value Health 2014;17:561-569.

37. McQueen RB, Ellis SL, Campbell JD, et al.: Costeffectiveness of continuous glucose monitoring and intensive insulin therapy for type 1 diabetes. Cost Eff Resour Alloc 2011;9:13.

38. Riemsma R, Corro Ramos I, Birnie R, et al.: Integrated sensor-augmented pump therapy systems [the $\operatorname{MiniMed}(\mathrm{R})$ Paradigm Veo system and the Vibe and G4(R) PLATINUM CGM (continuous glucose monitoring) system] for managing blood glucose levels in type 1 diabetes: a systematic review and economic evaluation. Health Technol Assess 2016;20:v-xxxi, 1-251.

39. Roze S, Saunders R, Brandt AS, et al.: Health-economic analysis of real-time continuous glucose monitoring in people with Type 1 diabetes. Diabetes Med 2015;32:618-626.

40. Roze S, Smith-Palmer J, Valentine W, et al.: Costeffectiveness of sensor-augmented pump therapy with low glucose suspend versus standard insulin pump therapy in two different patient populations with type 1 diabetes in France. Diabetes Technol Ther 2016;18:75-84.

41. Roze S, Smith-Palmer J, Valentine WJ, et al.: Long-term health economic benefits of sensor-augmented pump therapy vs continuous subcutaneous insulin infusion alone in type 1 diabetes: a U.K. perspective. J Med Econ 2016;19:236-242.

42. Watkins JB, Minshall ME, Sullivan SD: Application of economic analyses in U.S. managed care formulary decisions: a private payer's experience. J Manag Care Pharm 2006;12:726-735.

43. Shaya FT, Ohsfeldt RL: Bridging the gap between pharmacoeconomics and the real-world practice of managed care pharmacy. J Manag Care Pharm 2007;13:66-67.

44. McGregor M: Cost-utility analysis: use QALYs only with great caution. CMAJ 2003;168:433-434.

45. Polonsky WH, Hessler D: Perceived accuracy in continuous glucose monitoring: understanding the impact on patients. J Diabetes Sci Technol 2015;9:339-341.

46. Battelino T, Liabat S, Veeze HJ, et al.: Routine use of continuous glucose monitoring in 10501 people with diabetes mellitus. Diabet Med 2015;32:1568-1574.

47. Beck RW, Buckingham B, Miller K, et al.: Factors predictive of use and of benefit from continuous glucose monitoring in type 1 diabetes. Diabetes Care 2009;32:1947-1953.

48. Chase HP, Beck RW, Xing D, et al.: Continuous glucose monitoring in youth with type 1 diabetes: 12-month followup of the Juvenile Diabetes Research Foundation continuous glucose monitoring randomized trial. Diabetes Technol Ther 2010;12:507-515.

49. Kordonouri O, Pankowska E, Rami B, et al.: Sensoraugmented pump therapy from the diagnosis of childhood type 1 diabetes: results of the Paediatric Onset Study (ONSET) after 12 months of treatment. Diabetologia 2010; 53:2487-2495.

50. Laffel LM, Volkening LK, McMullen WJ, et al.: Improved CGM performance predicts CGM use and outcomes in pediatric patients with T1D. Paper presented at: Poster presented at the 76th Scientific Sessions of the American Diabetes Association; June 10-14, 2016; New Orleans, LA.

51. Raccah D, Sulmont V, Reznik Y, et al.: Incremental value of continuous glucose monitoring when starting pump therapy in patients with poorly controlled type 1 diabetes: the RealTrend study. Diabetes Care 2009;32:2245-2250.

Address correspondence to: Claudia Graham, PhD, MPH

DexCom

6340 Sequence Drive San Diego, CA 92121

E-mail: cgraham@dexcom.com 